\title{
Significados da água na visão de lideranças de saúde
}

\section{The meanings of water in the vision of health care leaders}

\author{
Regina Glaucia Ribeiro de Lucena \\ Doutora em Saúde Pública. Professora Adjunto I da Faculdade de \\ Farmácia, Odontologia e Enfermagem da Universidade Federal \\ do Ceará. \\ Endereço: Rua Alexandre Baraúna, 949, Rodolfo Teófilo, CEP 60430- \\ 160, Fortaleza, CE, Brasil. \\ E-mail: reginalucenaı®hotmail.com \\ Maria Tereza Pepe Razzolini \\ Doutora em Saúde Pública. Professora associada da Faculdade de \\ Saúde Pública da Universidade de São Paulo. \\ Endereço: Avenida Dr. Arnaldo, 715, Cerqueira César, CEP 01246- \\ 904, São Paulo, SP, Brasil. \\ E-mail: razzoliniळusp.br

\section{Léa Maria Bezerra de Menezes} \\ Doutora em Radiologia Odontológica. Professora Adjunta da Fa- \\ culdade de Farmácia, Odontologia e Enfermagem da Universidade \\ Federal do Ceará. \\ Endereço: Rua Alexandre Baraúna, 949, Rodolfo Teófilo, CEP 60430- \\ 160, Fortaleza, CE, Brasil. \\ E-mail: Ibezerrademenezesळyahoo.com.br
}

Regina Auxiliadora de Amorim Marques

Doutora em Saúde Pública. Assessora da Área Técnica de Saúde Bucal da Secretaria Municipal de Saúde de São Paulo.

Endereço: Rua General Jardim, 36, 5 andar, Centro, CEP OI223-oı, São Paulo, SP, Brasil.

E-mail: regina.a.marquesळuol.com.br

\section{Paulo Capel Narvai}

Doutor em Saúde Pública. Professor Titular da Faculdade de Saúde Pública da Universidade de São Paulo.

Endereço: Avenida Dr. Arnaldo, 715, Cerqueira César, CEP 01246904, São Paulo, SP, Brasil.

E-mail: pcnarvaiðusp.br

\section{Resumo}

Este estudo apresenta as percepções dos delegados à $13^{-}$Conferência Nacional de Saúde sobre os significados da água, no contexto da saúde pública, e sobre o papel do Estado na garantia do acesso à água tratada. Trata-se de uma pesquisa descritiva, com abordagem qualitativa, utilizando-se como técnica de processamento de depoimentos o Discurso do Sujeito Coletivo. A população de estudo consistiu dos delegados à $13^{\text {a }}$ Conferência Nacional de Saúde. Ao todo, participaram 310 desses delegados, distribuídos da seguinte maneira: 56 na etapa municipal, em Fortaleza (CE), 143 na estadual (Ceará) e 111 na nacional. Os dados foram coletados por meio de questionários e analisados utilizando-se, como estratégia metodológica, a análise do discurso. Os delegados percebem a água tratada como um bem essencial à saúde e à qualidade de vida, reconhecendo o problema da crescente escassez e degradação dos recursos hídricos, assim como as deficiências no acesso e no tratamento da água. Acreditam, ainda, que o Estado deve ter um papel protetor no provimento de água tratada, garantindo o acesso universal a esse bem. Pelos discursos, detectam-se fragilidades no tratamento da água e na vigilância sanitária, bem como nos mecanismos de informação sobre assuntos relativos à água de abastecimento público, o que aponta para a necessidade de uma participação mais efetiva da sociedade nos espaços deliberativos que lhe são concedidos para o exercício de sua cidadania.

Palavras-chave: Água potável; Tratamento da água; Qualidade da água; Vigilância Sanitária. 


\section{Abstract}

This study presents the delegates to the 13th National Health Conference perceptions on the meanings of water in the context of public health, and of the state's role in ensuring access to clean water. This is a descriptive study of qualitative approach, using the Discourse of Collective Subject as technique for processing the statements. The study population comprised 310 delegates to the 13th National Conference on Health, distributed as follows: 56 in municipal stage, Fortaleza (CE), 143 in the state stage (Ceará) and 111 in national stage. Data were collected by questionnaires and analyzed using discourse analysis as a methodological strategy. The delegates perceive treated water as an essential good for health and quality of life and welfare, whilst recognizing the problem of increasing scarcity and degradation of water resources and the deficiencies in access and treatment of water. They also believe that the state must have a protective role in providing clean water, ensuring universal access to that good. By the speeches, weaknesses could be detected in water treatment and health surveillance, as well as on the mechanisms of information on matters relating to public water supply; these indicatethe need for more effective participation of society in deliberative spaces that are granted for the exercise of their citizenship.

Keywords: Drinking Water; Water Treatment; Water Quality; Health Surveillance.

\section{Introdução}

A água é, conforme amplamente reconhecido, de modo praticamente axiomático, um recurso fundamental à vida humana, quer na dimensão biológica, quer na dimensão social. Utilizada em atividades diversas como a agricultura, a pecuária, a indústria e os serviços, sua abundância ou escassez podem ser fatores determinantes dos hábitos de consumo de uma comunidade (Dias, 2011). Ela pode ainda influenciar modos de vida, ajudando a construir laços sociais entre os homens e as comunidades e favorecer o desenvolvimento da cooperação e da solidariedade (UNESCO, 2003). A disponibilidade de água potável promove o desenvolvimento, é um indicador do progresso dos povos e se constitui em um direito humano fundamental, base inclusive do exercício de outros direitos (PNUD, 2006).

Com diferentes conotações, tanto no plano material como no imaginário das pessoas, a água se inscreve também no domínio do simbólico, enfeixando várias imagens e significados. Pode ser vista como "um elemento da vida que a encompassa e a evoca sob múltiplos aspectos, materiais e imaginários" (Cunha, 200o, p. 15). Tem ainda valor ecológico, social, econômico, político e cultural (Garcia, 2007).

Contudo, de forma preocupante, a água do planeta tende a escassear em virtude do crescimento demográfico, da urbanização, da expansão da agricultura e do grau de industrialização, o que vem gerando expectativas de acirramento da disputa por esse recurso e uma crise de abastecimento em dimensões mundiais (Reymão e Saber, 2009).

Mais de um bilhão de pessoas em todo o mundo não têm acesso à água tratada. Dessas, cerca de 19 milhões residem no Brasil (Rheingans e col., 2006). Segundo dados da Pesquisa Nacional de Saneamento Básico (IBGE, 2010), aproximadamente 12 milhões de residências no Brasil não têm acesso à rede geral.

O problema é mais crítico na Região Norte, onde 54,7\% dos domicílios encontram-se nessa situação, seguida das Regiões Nordeste (31,7\%), Centro-Oeste (18,0\%), Sul (15,8\%) e Sudeste (12,5\%). Em 16 das 27 Unidades da Federação, a proporção de domicílios sem oferta do serviço é igual ou superior ao da média do Brasil (21,4\%), sendo os Estados de Rondônia (73,4\%), Acre (64,2\%), Pará (63,6\%) e Amapá (59,4\%) 
os que mais sofrem com esse tipo de problema (IBGE, 2010).

Ainda segundo essa pesquisa, a maior parte dos municípios brasileiros $(87,2 \%)$ distribui a água totalmente tratada. Nos demais $12,8 \%$, o tratamento é apenas parcial em 6,2\% e, em 6,6\%, não há qualquer tratamento.

Mesmo países com grande disponibilidade hídrica podem apresentar problemas de escassez, devido a causas naturais, à excessiva demanda ou ao desperdício. A preocupação com a degradação e a escassez dos recursos hídricos tem deixado de ser uma bandeira de luta apenas de ambientalistas, para assumir lugar de destaque na agenda de autoridades, comunidade científica e sociedade (Moraes e Jordão, 2002; Selborne, 2002).

Reymão e Saber (2009) veem sérios problemas na gestão dos recursos hídricos no Brasil, pois além das elevadas taxas de desperdício, há carência de investimentos no meio rural e de planejamento, prevalecendo a falta de infraestrutura, o que restringe os direitos de acesso à água de grande parte da população. A fragmentação de políticas públicas e a carência de instrumentos de regulamentação e regulação também estão entre os fatores relacionados ao déficit dos serviços de água e esgoto no nosso país (Nascimento e Heller, 2005).

Segundo Razzolini e Günther (2008), a compreensão dos níveis de acesso à água (básico, intermediário e ótimo) é essencial na avaliação de intervenções direcionadas à população que sofre com a escassez desse recurso. Esses níveis são influenciados pela distância percorrida e pelo tempo gasto para se atingir a fonte de água, podendo refletir diretamente na ocorrência de enfermidades que poderiam ser evitadas, como diarreias, cólera, dengue e outras (Teixeira e Pungirum, 2005).

Para Pontes e Schramm (2004), o problema do acesso à água deve ser visto como questão de saúde pública, podendo ser abordado sob a ótica da bioética de proteção, uma ética da responsabilidade social, em que o Estado deve se basear para assumir suas obrigações sanitárias para com as populações humanas (Schramm e Kottow, 2001). Para esses autores, as medidas que legitimam o papel do Estado como protetor da saúde pública (no que se refere à água potável) devem ser aquelas que possibilitem a todo cidadão dispor de água em quantidade suficiente e qualidade adequada para atender às suas necessidades básicas. Cabe ao Estado identificar as situações em que há desigualdades de acesso e desenvolver políticas públicas para resolver esses problemas.

Tomando-se como base esse contexto, procurou-se conhecer as opiniões e percepções dos delegados à $13^{\text {a }}$ Conferência Nacional de Saúde acerca da água para consumo humano e do acesso à água tratada. Esses delegados são atores sociais qualificados, diretamente envolvidos em processos decisórios sobre saúde e sistemas de saúde no Brasil, muitos deles integram conselhos de saúde, em âmbitos municipal e estadual. As opiniões e percepções dessa parcela da sociedade são de fundamental importância para que se compreendam seu papel e responsabilidade, enquanto interlocutora do Estado, e enquanto formadora da opinião pública, no direcionamento de políticas públicas de saúde orientadas para o bem-estar da população e para o desenvolvimento sustentável.

\section{Método}

Este estudo faz parte de uma investigação sobre fluoretação das águas de abastecimento público no Brasil, junto aos delegados à $13^{\underline{a}}$ Conferência Nacional de Saúde. Tendo em vista a natureza do objeto de investigação, optou-se por realizar pesquisa descritiva, com abordagem qualitativa, e população de estudo definida por conveniência. A participação do delegado em etapa anterior da referida conferência (municipal e estadual) foi utilizada como critério de exclusão. Ao todo, foram 310 delegados, distribuídos da seguinte maneira: 56 na etapa municipal (Fortaleza), 143 na estadual (Ceará) e 111 na nacional, todas realizadas em 2007 (Tabela 1 ).

Na coleta das informações, utilizou-se um questionário semiestruturado, contendo 19 questões, que foram respondidas por 72 delegados gestores/ prestadores de serviços de saúde, 91 trabalhadores de saúde e 147 usuários dos serviços de saúde. Neste estudo foram analisados os resultados relativos às opiniões e percepções dos delegados acerca de assuntos relativos à água e ao acesso à água tratada, a partir das respostas emitidas pelos participantes ao serem questionados conforme segue: a) Sabemos 
Tabela I - Distribuição dos delegados à $13^{\mathrm{a}}$ Conferência Nacional de Saúde, participantes da pesquisa, segundo segmento e etapa. Brasil, 2007

\begin{tabular}{cccccc} 
& \multicolumn{2}{c}{ Segmento } & \multicolumn{2}{c}{ Total } \\
& Gestor/prestador & Trabalhador & Usuário & $n$ & $\%$ \\
Municipal & $n$ & $n$ & $n$ & 56 & 18,1 \\
Estadual & 9 & 19 & 28 & 143 & 46,1 \\
Nacional & 32 & 47 & 64 & 111 & 35,8 \\
\hline Total $n$ & 31 & 25 & 55 & 310 & - \\
$\%$ & 72 & 91 & 147 & - & 100,0 \\
\hline
\end{tabular}

que, além de ser indispensável para a vida humana, a água é importante para a saúde. Você gostaria de comentar sobre isso?; b) Na sua opinião, o que o Estado, os governos deveriam fazer para garantir água para todas as pessoas?; e, c) Você gostaria de comentar alguma coisa sobre tratamento da água?

Para tratamento dos dados, utilizou-se a técnica do Discurso do Sujeito Coletivo (DSC), que consiste num conjunto de procedimentos de tabulação e organização de dados discursivos provenientes de depoimentos orais ou não. O DSC permite reconstituir um "sujeito coletivo" que fala como se fosse um indivíduo, mas veicula uma representação com conteúdo ampliado (Lefèvre e Lefèvre, 2003; Lefèvre e col., 2009). Essa técnica é compatível e ajusta-se bem a estudos como este, cujo projeto foi aprovado pelo Comitê de Ética em Pesquisa da Faculdade de Saúde Pública da Universidade de São Paulo, sob o Parecer $\mathrm{n}^{\mathrm{0}} \mathbf{1 . 7 2 3}$.

Após leitura das informações contidas nos questionários, identificaram-se as expressões-chave (transcrições literais de partes dos depoimentos), as quais permitem resgatar o essencial do conteúdo discursivo. Estas foram agrupadas conforme a ideia central (IC) que expressavam, formando-se os discursos-síntese ou os discursos do sujeito coletivo (Lefèvre e col., 200o). Os DSCs foram construídos a partir de agregações dos discursos de cada segmento de delegados (gestores/prestadores, trabalhadores e usuários), podendo-se observar, assim, similaridades e antagonismos entre eles. Os discursos foram analisados segundo o referencial das representações sociais sobre o acesso à água tratada (Lefèvre e Lefèvre, 2003).

\section{Resultados}

Os resultados são apresentados de modo estruturado, em torno dos seguintes eixos: a) importância da água para a saúde; b) o papel do Estado na garantia do acesso à água; e, c) importância do tratamento da água.

\section{A importância da água para a saúde}

As ideias centrais acerca da importância da água para a saúde, com os respectivos DSCs, são descritas a seguir:

Ideia Central 1: A água é essencial a todos os seres vivos

DSC 1 - Gestor/Prestador: A importância da água é indiscutível. Água é vida e alimento, é indispensável para a vida humana e toda biodiversidade. É importante como qualidade de vida, principalmente na medida em que podemos sobreviver vários dias sem comer, mas não sem água. É responsável por grande percentual da constituição corpórea (nosso corpo é constituído de 7o\% dela), responsável por termorregulação, hidratação, meio de condução de substâncias; auxílio na higiene corporal e ambiental; promove o desenvolvimento de plantas, influencia na regulação da temperatura do ambiente no planeta; promove energia hidroelétrica. Por esta razão ela não pode faltar.

DSC 2 - Trabalhador de saúde: Áágua éfundamental para a vida humana, sem ela não somos ninguém, não haveria vida no planeta. Nosso corpo tem $70 \%$ de água; não conseguimos sobreviver sem água. Além da questão fisiológica, é importante para a higiene corporal, alimentação, hidratação, sendo sempre 
necessária a sua reposição. Sem água não é possível se ter saúde, pois não há condições de boa higiene, consequentemente, as doenças se disseminam muito mais, por isso temos que reivindicar o uso da água. $\varepsilon$ É um elemento básico que favorece of funcionamento de diversos setores: economia, lazer, uso e fluxo comercial, regula o equilibrio no ecossistema.

DSC 3 - Usuário: A água é essencial, como o ar que respiramos. Sem dúvida, évital para qualquer espécie, pois através da água que flore a vida e a prova disso é que a Terra é coberta na maioria por este líquido maravilhoso. Sem ela não há saúde, não há desenvolvimento, não há crescimento. $\varepsilon$ indispensável à manutenção da vida humana e outras formas devida, pois somos $70 \%$ de água. É da água que vem uma série de outras substâncias que são essenciais ao metabolismo celular e, consequentemente, tecidos, órgãos e sistemas orgânicos, além de hidratare evitar disfunções renais graves e óbitos decorrentes. Ela é quem nos fortalece, energizando-nos, dando suporte ao funcionamento saudável do nosso corpo.

Ideia Central 2: A população precisa preservar a água

DSC 1 - Gestor/Prestador: A água é essencial à vida e devemos preservá-la. É um recurso natural em processo de escassez, se não tomarem medidas, poderá ser bem difícil o futuro. Devemos ter a consciência de sua importância, evitando o desperdício. Devemos conscientizar a população quanto à economia da água, há necessidade de maior orientação para manuseio da água, e de penalidades para o desrespeito à sua utilização. O desperdício que é feito pelo usuário torna-se preocupante. Continuando a seguir neste ritmo, dentro de alguns anos o preço de um copo d'água será igual ao de um carro popular. Tenho consciência disso e me preocupa a forma como o ser humano lida com esse precioso bem.

DSC 2 - Trabalhador de saúde: A água é um bem natural que deve ser respeitado para ser bem utilizado. $\varepsilon$ essencial para a vida, para a natureza. $O$ que se percebe é que este recurso vem sendo desperdiçado sem critérios e a cada instante a água está ficando cada vez mais escassa, principalmente para o consumo humano. Se não cuidarmos dos mananciais teremos muitos problemas, certamente, mas não há uma conscientização da população sobre o risco de ficarmos sem água, só se percebe quando falta. Muito se tem falado sobre a água, muito se tem divulgado sobre a importância, mas a conscientização em forma de atos, cadê? É um bem importantíssimo e precisa ser amplamente discutido em escolas, estabelecimentos de saúde, principalmente em relação ao futuro. Não se compreende já que é essencial e indispensável, por que tanto descaso.

DSC 3 - Usuário: Água potável e de qualidade é um bem que se torna muito valioso e cada vez mais escasso. Temos muito desperdício e falta de informação sobre o assunto de água potável. As gerações futuras vão sofrer, as fontes já estão diminuindo devido à queima das florestas. Num futuro bem próximo, nós ficaremos sem água, por haver tanto desperdício por pessoas incompreensiveis. Precisamos promover muitas pesquisas no sentido de propiciar água no estado necessário à vida, encontrando meios de purificar, dessalinizar e preservá-la utilizável. Se a gente não se tornar um fiscal permanente da nossa água, vamos sofrer muito no futuro. Cuidar desse precioso líquido é um desafio para todos nós.

Ideia Central 3: Apesar da importância da água para a saúde e a qualidade de vida das pessoas, esse assunto não é prioridade do governo

DSC 1 - Usuário: Apesar da importância da água para a saúde e qualidade de vida, ainda não é prioridade dos governos municipais e estaduais. Muitas comunidades do interior ainda sofrem com a falta d'água potável. Enquanto Sul e Sudeste têm enchentes, a região seca está se desgastando. A mídia mostra gado morrendo. Isto afeta desde o empresário até o empregado. O governo deveria tratar com mais respeito a questão da água, cavando poços, fazendo açudes e cuidando. Hoje há um descaso. A água é indispensável para a população e a vida humana, mas uma água de qualidade, essa o governo não oferece e pagamos caro. Governantes! Olhem para esta questão da ÁGUA com carinho! Água sem qualidade! Não dá!

\section{O papel do Estado na garantia do acesso à água}

As ideias centrais e DSCs acerca do papel do Estado na garantia do acesso à água foram:

Ideia Central 1: Políticas direcionadas para a preservação do meio ambiente e o uso racional da água 
DSC 1 - Gestor/Prestador: Em primeiro lugar, lançar campanhas de conscientização da sociedade, no sentido de preservar, economizar e respeitar este bem, que é coletivo e passível de faltar ou ser racionado, se não fizermos bom uso dele. Editar leis a serem cumpridas, incentivando o uso racional da água. Implementar política pública para proteção das nascentes e controle mais efetivo dos resíduos industrializados antes de lançar na água. Investir em pesquisas, para preservação do meio-ambiente. Políticas públicas de preservação ambiental rigorosas e educativas permanentes.

DSC 2 - Trabalhador de saúde: Políticas de governo que conscientizem a população sobre sua importância e o uso racional adequado e sobre tratamento de esgotos despejados em nossos rios. Preservar as fontes, os mananciais e nascentes, cuidar do meio ambiente antes de tudo, para garantirágua às atuais e futuras populações. Distribuir informação sobre a situação da água e educar as pessoas a respeito do desperdício de água. Punir com seriedade. Proibir o desmatamento e as queimadas e plantar mais árvores. Desenvolver a médio e longo prazo programas de educação permanente para os consumidores. Garantir a sustentabilidade ambiental e humana.

DSC 3 - Usuário: Em primeiro lugar, garantir a preservação da água. Ter uma política ambiental firme. Não deixar os interesses econômicos tomarem conta da política ambiental. Incentivar e promover o uso racional da água; exigir das empresas e grandes usuários tratamento da água utilizada para devolvê-la limpa à natureza. Promover leis que incentivem a preservação. Efetivar uma política pública de defesa do meio ambiente, investir na agroecologia, defesa e conservação das nascentes, coibir a perfuração de poços artesianos privados. Projetos $e$ programas voltados à conscientização da sociedade consumidora de recursos hídricos, haja vista o nivel preocupante de desperdício do bem e uma projeção desastrosa de racionamento de água em 50 anos. Investir maciçamente no trabalho de educação em saúde ambiental desde a pré-escola, para que haja conscientização das comunidades no sentido de se considerarem corresponsáveis. Não só o Estado,nem os governos, mas sim todos nós devemos preservar, racionar e valorizar este produto tão essencial para nossa saúde.
Ideia Central 2: Políticas voltadas para a descoberta de fontes alternativas de abastecimento d'água.

DSC 1 - Gestor/Prestador: Investir na formação de novas fontes de recursos hídricos, buscando alternativas de fontes d'água (exemplo: dessalinização da água), ampliar pesquisas de novos mananciais; e ensinar às pessoas a captação e armazenamento da água de chuva. Uma política voltada para isto.

DSC 2 - Trabalhador de saúde: Nós sabemos que, quando há inverno se perde muita água. Como solução, seria construir reservatórios e procurar meios de reaproveitar as águas dos esgotos, mar, rios poluídos, tornando-as potáveis novamente. Pensar projetos de aproveitamento de fluxo de água natural.Deveriam priorizar recursos e investimentos nesse setor. As possibilidades são inúmeras, desde construção de adutoras à dessalinização da água. O que falta é ação incisiva sobre a questão.

DSC 3 - Usuário: Deve-se desenvolver ações que garantam a permanência da água já existente em nosso solo. Deveria, no planejamento, destinar uma parte do dinheiro para o aproveitamento do lençol freático. Gerir melhor as fontes de água existentes, criando mecanismos fiscalizadores mais sérios $e$ punitivos. Nas regiões de mais dificuldade deveriam fazer estudos para possibilitar água ou captação da água. Transposições dos grandes rios até tentar dessalinizar a água do mar. Procurar alternativas para o uso da água em segmentos aonde a água não precisa ser potável. Aproveitar as águas das chuvas, porque quando chove tem muita água.

Ideia Central 3: Políticas públicas voltadas para a não mercantilização da água

DSC 1 - Gestor/Prestador: Não mercantilizar. Entendo que água, que é um direito universal, deveria ser fornecida gratuitamente ou com tarifas mais baratas, taxas racionais, proporcionais ao tipo de uso e volume. Água potável, clorada efluorada. Todos precisamos da água, mas para alguns de nossos estados brasileiros, água é luxo. Ainda existem muitas cidades e localidades que ainda não têm esse acesso e a oferta desse direito.

DSC 2-Usuário: A água deve ser entendida como um bem público a que todos devem ter acesso de forma equitativa, e não apenas quem tem poder aquisitivo melhor. A água, enquanto elemento indispensável 
para produção e reprodução da vida humana, tem sido utilizada como mercadoria, inclusive sob o discurso do cuidado à saúde. Por uma questão de ética devemos respeitar esse bem que a natureza nos oferece e defender o direito de todos os seres vivos terem acesso a ela. Cabe aos estados nacionais a governança sobre o acesso a este patrimônio. Pensar mais como o povo pobre sofre e baixar os impostos. Oferecer água a baixo custo. Baratear tarifas, tendo a água como bem público e não produto capitalizado e privatizado.

\section{Importância do tratamento da água}

As ideias centrais e discursos do sujeito coletivo referentes ao tratamento da água são expostas a seguir:

Ideia Central 1: A população não está bem informada sobre o tratamento e a qualidade da água que consome

DSC 1 - Trabalhador de saúde: A água tem que ser limpa para o consumo humano. Infelizmente não domino esse assunto, não entendo o método de tratamento, não sei muito a respeito. Gostaria que fosse mais aberto à comunidade, não nos deixam clareza sobre a qualidade dela. Que fosse mais transparente e acessível com relação ao flúor e ao cloro.

DSC 2 - Usuário: Não possuo elementos técnicos para discutir o tratamento, sinceramente, não sei como éfeito, no nosso Estado. Nós usuários não temos clareza como se trata nossa água, não ensinam limpeza da caixa d'água e nem fazem nos setores do executivo, escolas e creches, etc. Há necessidade de buscar e difundir com mais ênfase as soluções encontradas para usar e tratar a água. A empresa de abastecimento o o governo precisam esclarecer a população sobre os produtos que estão sendo utilizados. A partir daí, a população vai se interessar mais.

Ideia Central 2: Falta monitoramento e controle no tratamento da água

DSC 1 - Gestor/Prestador: É previsto no SUS, a fiscalização e promoção de tratamento das águas, a quantidade de dosagem certa de íons para o sistema de abastecimento no tratamento das águas. Água para consumo humano tem que ser tratada e os teores de cloro residual e de flúor têm que ser respeitados. $O$ tratamento deve obedecer aos padrões de consumo e segurança e tem que ser monitorado constantemente, não só os reservatórios, mas sim na fonte das águas (captação). Não há monitoramento e fiscalização efetiva do Estado. Acho que o Estado/governo não dá conta de monitorar a qualidade. Vejamos o exemplo da fluoretação. Se olharmos para o índice mensal, sobe e desce e não percebemos mobilização nenhuma da vigilância sanitária. Faz-se necessário o controle da água pela vigilância sanitária e pela comunidade. Acho que nas estações de tratamento o processo acontece positivamente, no entanto é necessário análise, na rede de abastecimento e no manuseio da água. Deveriam controlar mais e divulgar mais os resultados.

DSC 2 - Trabalhador de saúde: A maioria dos municípios só possui água tratada na zona urbana, enquanto a zona rural fica esquecida e sem nenhum controle da qualidade da água que está sendo consumida. Deve haver fiscalização nos reservatórios onde são acumulados a água a ser distribuída. Verificar com cuidado a dosagem das substâncias que forem colocar na água. O cloro está demasiado nas torneiras. Deve ser controlado com análises periódicas, ter fiscalização para isto. Fazer, periodicamente, a análise bacteriológica da água, ou seja, levar para o Laboratório Central (LACEN). Deveria haver mais controle por parte da vigilância sanitária, principalmente em relação ao flúor, mas também em consideração aos agrotóxicos. Acredito que há muitas falhas no controle do tratamento da água nos municípios, necessitando de um melhor investimento e vigilância.

DSC 3 - Usuário: A população tem como segurança de água potável a análise do tratamento. Onde o povo não tem certeza se a água é adequada ao uso humano e animal, que fosse feito exame de laboratório. Deve ser tratada e preservada, não só colocando cloro como fazem, mas fazendo revisão nos reservatórios permanentemente, fiscalização contínua, para observar a qualidade e os recursos adequados se estão sendo utilizados, garantindo assim o seu controle social. Gostaria de comentar sobre a fluoretação da água que está sendo feita sem controles, devendo provocar alguns problemas de saúde para a população, como a fluorose. 


\section{Discussão}

\section{A importância da água para a saúde}

Todos os segmentos enfatizaram a importância da água tratada na saúde e qualidade de vida da população.

Na relação do ser humano com o ambiente que o cerca, a água pode afetar a saúde de várias maneiras: por meio da ingestão direta, na preparação de alimentos, na higiene pessoal, na agricultura, na higiene do ambiente, nos processos industriais ou nas atividades de lazer (Cairncross e Feachem, 2005). Somente a partir da década de 1980 , denominada a "Década Internacional do Abastecimento de Água e do Esgotamento Sanitário", é que se pôde observar um esforço mais sistemático de compreensão das relações entre o saneamento e a saúde, com a realização de estudos epidemiológicos que avaliavam essa relação (Heller, 2006).

A preocupação com a escassez, o desperdício e a degradação desse recurso também esteve presente nos discursos dos delegados, que creem nas atividades educativas como instrumento eficaz para a preservação ambiental, que é vista como sendo responsabilidade de todos, e não apenas do Estado. Emergiu dos discursos dos usuários certa insatisfação com o "descaso do governo", que não vem tratando essa questão "com prioridade".

Quanto aos gestores/prestadores, a preocupação com a preservação da água está para além de sua crescente escassez, perpassando também pelos aspectos econômicos. Para esse segmento, a melhoria na saúde e qualidade de vida atribuída ao consumo de água de boa qualidade implica economia para o governo, em termos de gastos com saúde. Esse enfoque não apareceu nos discursos dos usuários nem dos trabalhadores de saúde.

O abastecimento de água tem preocupado, cada vez mais, os gestores públicos, uma vez que a falta de acesso à água é considerada fator de risco à saúde, no contexto dos agravos à saúde atribuídos ao saneamento ambiental deficiente, além de limitar o desenvolvimento, de acordo com a Organização Mundial da Saúde (Razzolini e Günther, 2008).

Uma mudança nas crenças utilitárias aumenta os níveis de motivação para a preservação da água, pois quanto mais os indivíduos pensam na água como um recurso ilimitado, menos eles se sentem motivados para conservá-la (Corral-Verdugo, 2003). Assim, uma forma de mudar crenças ambientais pode se dar por meio da educação ambiental dirigida a instigar os cidadãos a desenvolver uma visão pró-ecológica da água como um recurso limitado (Legault e Pelletier, 200o). Contudo, para que essa consciência sobre a responsabilidade do ser humano diante do meio ambiente se efetive, é preciso o envolvimento do sistema educativo nos problemas do cotidiano da cidade, para que a sociedade como um todo assuma sua responsabilidade educativa (Kuhnen e Becker, 2010).

\section{O papel do Estado na garantia do acesso à água}

Políticas voltadas para o saneamento básico, a ampliação da rede de abastecimento e a descoberta de fontes alternativas de abastecimento d'água foram mencionadas pelos três segmentos entrevistados.

Pontes e Schramm (2004) consideram como medidas legitimadoras do papel do Estado, enquanto protetor da saúde pública, aquelas que proporcionem a todo cidadão o acesso à água em quantidade suficiente e qualidade adequada para atender às necessidades básicas. Para esses autores, o enfrentamento dos problemas de acesso à água potável envolve dois níveis de resolução. Num primeiro nível, deve-se considerar o caráter universal, de modo que se garanta, a cada indivíduo, o acesso a sistemas públicos de abastecimento de água. Num segundo nível, é necessário resolver problemas de infraestrutura do ambiente domiciliar, de modo a compensar as desvantagens dos menos favorecidos, que não dispõem de condições para o armazenamento e manejo adequados da água em seus domicílios.

Segundo Cardoso (2006), a água não é um bem econômico, portanto não se enquadra nas relações de mercado. Em oposição, Torres (2007) refere que a água, como mercadoria, com direito privatizado de uso, tomou expressão legal no corpo das leis, dos decretos, dos regulamentos e das normas. Os regimentos de gestão pública da água sempre estiveram presentes em todos os tempos e em todas as sociedades.

Segundo Barros e Amin (2008), é preciso que se entenda que, em tese, a água é considerada como um bem comum, à qual todos têm acesso. Ou seja, é de 
modo geral entendida como um patrimônio comum, um recurso de toda nação que dele dispõe. No entanto, a confrontação da disponibilidade da água com suas demandas tende a acarretar a escassez desse recurso. Desse modo, se fortalece a tendência a não mais considerar a água um bem comum, e sim um bem com valor econômico e um recurso estratégico essencial ao desenvolvimento econômico e social dos países. Contudo, essa transformação de um bem comum, um direito humano, em um bem econômico, em uma espécie de commodity, a ser negociada no mercado, tem importantes implicações para a saúde pública e requer atenção permanente das sociedades e governos.

\section{Tratamento da água}

Insatisfeitos e inseguros com o monitoramento da qualidade da água, os três segmentos de delegados conhecem o papel da vigilância sanitária, mas não a consideram eficaz. Acreditam ser um direito da sociedade o acesso às informações. Entretanto, não veem cobranças por parte da sociedade, o que pode denotar fragilidades em sua participação e envolvimento nas práticas fiscalizatórias relativas à água de consumo humano.

De fato constataram-se falhas com relação ao monitoramento da qualidade da água em alguns municípios brasileiros, especialmente quanto aos teores do flúor, que frequentemente estão fora dos parâmetros recomendados, além da descontinuidade de sua adição na água (Maia e col., 2003; Silva e col., 2004; Lima e col., 2004; Saliba e col., 2006; Toassi e col., 2007; Frazão e col., 2013). Esse fato é inadequado em termos de saúde pública, haja vista que a eficácia da fluoretação da água como medida preventiva depende da manutenção dos teores de flúor preconizados e da continuidade do processo.

$\mathrm{O}$ direito do cidadão de receber as informações sobre os padrões de potabilidade e a qualidade da água que consome já estava previsto na Portaria № 518/2004 (Brasil, 2004). O Decreto № 5.440, de 4/5/2005 (Brasil, 2005), fixa como devem ser esses procedimentos informativos à população, tanto por parte dos responsáveis pelos sistemas de abastecimentos de água como pelas autoridades federais, estaduais e municipais responsáveis pela vigilância da qualidade de água. A falta de informação sobre a qualidade da água de abastecimento público e a crise de credibilidade dos órgãos de vigilância sanitária contribuem para estimular o consumo de água engarrafada ("mineral”) no Brasil. Estudos referem que este produto foi o que apresentou maior volume de crescimento entre as famílias brasileiras nos últimos trinta anos, uma vez que o consumo passou de o,32 litros per capita/ano em 1974/1975 para 18,541 litros per capita/ano em 2002/2003 (Pitaluga, 2006).

Da mesma forma que é de grande importância o investimento realizado pelas companhias de saneamento para melhorar as tecnologias do sistema de abastecimento, é também relevante que as informações cheguem até a população, o que contribui para elevar a confiança na água do sistema público. Tal prática pode resultar em maior participação e apoio comunitário, bem como em maior envolvimento da sociedade na gestão dos serviços de saneamento. A necessidade do envolvimento da comunidade em questões ambientais tem sido largamente reconhecida na literatura (Nicholson e col, 2002).

Heller (2006) assinala a importância da participação da comunidade na gestão e na tomada de decisões sobre o serviço de abastecimento de água. Enfatiza que essa participação tem sido crescentemente reconhecida como "um requisito para o bom êxito do serviço e um imperativo democrático, ou seja, uma demanda legítima de uma sociedade democrática, que determina a abertura de canais para a participação do cidadão" (p. 841).

Os participantes deste estudo indicaram a necessidade de que as entidades municipais, estaduais e federais desenvolvam estratégias que possibilitem levar à população informações sobre a água que lhe é disponibilizada. Para isso devem utilizar mecanismos baseados no diálogo, com vistas ao aumento da confiança na qualidade da água de consumo humano. Nessas estratégias, que devem valorizar a água, como elemento de promoção da saúde, são indispensáveis o envolvimento e a participação dos agentes comunitários de saúde e dos conselhos de saúde.

\section{Considerações finais}

Houve reconhecimento do problema da crescente escassez de água e da degradação dos recursos 
hídricos, acreditando-se no processo educativo, com foco na conscientização da população, como estratégia importante para a preservação ambiental e o uso racional da água. Os participantes deste estudo consideram que, para legitimar o papel protetor no provimento de água tratada, o Estado deve reconhecer as situações de desigualdades de acesso e desenvolver políticas públicas compensatórias.

O grande déficit no acesso das populações à água tratada, as deficiências no tratamento e a fragilidade da vigilância sanitária são situações reconhecidas pelos delegados, o que aponta para a necessidade de se rever o papel do Programa de Vigilância da Qualidade da Água para Consumo Humano (VIGIÁGUA), e de se criar mecanismos que tornem suas ações mais efetivas no exercício da vigilância da qualidade da água. É necessário, também, manter a população bem informada com relação à água que consome, criando-se e democratizando-se ferramentas de divulgação das informações.

Os princípios que norteiam o Sistema Único de Saúde estabelecem e fortalecem diversos direitos de cidadania, com avanços na participação popular e na descentralização do poder, no que concerne às decisões de saúde, meio ambiente, saneamento, habitação, entre outros. Essa conquista social, entretanto, tem sido insuficiente para garantir o exercício efetivo da cidadania nesse setor, de acordo com os segmentos ouvidos nesta pesquisa, que reiteraram ser preciso que a sociedade, por meio dos atores sociais que a representam, participem de maneira mais efetiva nos espaços deliberativos que a lei lhes assegura e, desse modo, exerçam com mais propriedade sua cidadania.

Por fim, houve reconhecimento de que a universalização do acesso à água tratada ainda não é uma realidade no Brasil, cabendo à sociedade, por meio da educação e da participação social, lutar em busca de melhorias nesse acesso e monitorar as políticas públicas voltadas a garantir o acesso a esse bem público indispensável à vida.

\section{Referências}

BARROS, F. G. N.; AMIN, M. M. Água: um bem econômico de valor para o Brasil e o mundo. Revista Brasileira de Gestão e Desenvolvimento Regional, Taubaté, v. 4, n. 1, p. 75-108, 2008.
BRASIL. Ministério da Saúde. Portaria $n^{0} 518$, de 25 de março de 2004. Estabelece os procedimentos e responsabilidades relativas ao controle da vigilância da qualidade da água para o consumo humano e seu padrão de potabilidade e dá outras providências. Diário oficial da União, Brasília, DF, 16 mar. 2004. Seção 1, p. 266-270.

BRASIL. Presidência da República. Decreto $\mathrm{n}^{0}$ 5.440, de 5 de maio de 2005. Estabelece definições sobre o controle de qualidade da água de sistemas de abastecimento e institui mecanismos e instrumentos para divulgação de informação ao consumidor sobre a qualidade da água para consumo humano. Diário oficial da União, Brasília, DF, 6 maio 2005. Disponível em: <http://www.planalto.gov.br/ccivil_o3/_Ato20042006/2005/Decreto/D5440.htm>. Acesso em: 4 mar. 2008.

CAIRNCROSS, S.; FEACHEM, R. Environmental health engineering in the tropics: an introductory text. New York: John Wiley \& Sons, 2005.

CARDOSO, J. S. A água como patrimônio comum da humanidade. Boletim Jurídico, Uberaba, v. 4 n. 186, 2006. Disponível em: < http:// www.boletimjuridico.com.br/doutrina/texto. asp?id=1395>. Acesso em: 14 out. 2013

CORRAL-VERDUGO, V. Determinantes psicológicos e situacionais do comportamento de conservação de água: um modelo estrutural. Estudos de Psicologia, Natal, v. 8, n. 2, p. 245-252, 2003.

CUNHA, L. H. O. Significados múltiplos das águas. In: DIEGUES, A. C. (Org.). A imagem das águas. São Paulo: Hucitec, 200o. p. 15-25.

DIAS, R. B. Tecnologias sociais e políticas públicas: lições de experiências internacionais ligadas à água 2011. Inclusão Social, Brasília, DF, v. 4, n. 2, p. 56-66, 2011.

FRAZÃO, P. et al. Fluoretação da água e insuficiências no sistema de informação da política de vigilância à saúde. Revista da Associação Paulista de Cirurgiões-Dentistas, São Paulo, v. 67, n. 2, p. 94-100, 2013. 
GARCIA, L. Água em três movimentos: sobre mitos, imaginário e o papel da mulher no manejo das águas. Gaia Scientia, João Pessoa, v. 1, n. 1, p. 17-23, 2007.

HELLER, L. Gestão dos serviços. In: HELLER, L; PÁDUA, V. L. (Org.). Abastecimento de água para consumo humano. Belo Horizonte: UFMG, 2006. p. 817-844.

IBGE - INSTITUTO BRASILEIRO DE GEOGRAFIA E ESTATÍSTICA. Pesquisa nacional de saneamento básico. Rio de Janeiro, 2010. Disponível em: <http://www.ibge.gov.br/home/ estatistica/populacao/condicaodevida/pnsb20o8/ PNSB_2008.pdf>. Acesso em: 2 jul. 2011.

KUHNEN, A.; BECKER, S. M. S. Psicologia e meio ambiente: como jovens e adultos representam água de abastecimento. Psico, Porto Alegre, v. 41, n. 2, p. 160-167, 2010.

LEFÈVRE, F.; LEFÈVRE, A. M. C. O discurso do sujeito coletivo: um novo enfoque em pesquisa qualitativa (desdobramentos). Caxias do Sul: EDUCS, 2003.

LEFÈVRE, F.; LEFÈVRE, A. M. C.; MARQUES, M. C. C. Discurso do sujeito coletivo, complexidade e auto-organização. Ciência \& Saúde Coletiva, Rio de Janeiro, v. 14, n. 4, p.1193-1204, 2009.

LEFÈVRE, F.; LEFÈVRE, A. M. C.; TEIXEIRA, J. J. V. O discurso do sujeito coletivo: uma nova abordagem metodológica em pesquisa qualitativa. Caxias do Sul: EDUCS, 2000.

LEGAULT, L.; PELLETIER, L. Impact of an environmental education program on students' and parents' attitudes, motivation, and behaviors. Canadian Journal of Behavioural Science, Otawa, v. 32, n. 4, p. 243-250, 2000.

LIMA, F. G. et al. Vinte e quatro meses de heterocontrole da fluoretação das águas de abastecimento público de pelotas, Rio Grande do Sul, Brasil. Cadernos de Saúde Pública, Rio de Janeiro, v. 2O, n. 2, p. 422-429, 2004.

MAIA, L. C. et al. Controle operacional da fluoretação da água de Niterói, Rio de Janeiro, Brasil. Cadernos de Saúde Pública, Rio de Janeiro, v. 19, n. 1, p. 61-67, 2003.
MORAES, D. S. L.; JORDÃO, B. Q. Degradação de recursos hídricos e seus efeitos sobre a saúde humana. Revista de Saúde Pública, São Paulo, v. 36, n. 3, p. 370-374, 2002.

NASCIMENTO, N. O.; HELLER, L. Ciência, tecnologia e inovação na interface entre as áreas de recursos hídricos e saneamento. Engenharia Sanitária e Ambiental, Rio de Janeiro, v. 10, n. 1, p. 36-48, 2005.

NICHOLSON, E.; RYAN, J.; HODGKINS, D. Community data: where does the value lie?: assessing confidence limits of community collected water quality data. Water Science and Technology, Washington, DC, v. 45, n. 11, p. 193200, 2002.

PITALUGA, C. M. Análise dos fatores que influenciam o consumo de água mineral. 2006. Dissertação (Mestrado em Agronegócios) Departamento de Economia e Administração da Universidade Federal de Mato Grosso, Campo Grande, 2006.

PONTES, C. A. A.; SCHRAMM, F. R. I. Bioética da proteção e papel do Estado: problemas morais no acesso desigual à água potável. Cadernos de Saúde Pública, Rio de Janeiro, v. 20, n. 5, p. 13191327, 2004.

PNUD - PROGRAMA DAS NAÇÕES UNIDAS PARA O DESENVOLVIMENTO. A água para lá da escassez: poder, pobreza e a crise mundial da água. Nova Iorque, 20o6. Disponível em: <http://hdr.undp.org/en/media/o1_HDRo6\%20 frontmatter_PT_revCA.pdf $>$. Acesso em: 23 maio 2013.

RAZZOLINI, M. T. P.; GÜNTHER, W. M. R. Impactos na saúde das deficiências de acesso a água. Saúde e Sociedade, São Paulo, v. 17, n. 1, p. 21-32, 2008.

REYMÃO, A. E.; SABER, B. A. Acesso à água tratada e insuficiência de renda duas dimensões do problema da pobreza no Nordeste Brasileiro sob a óptica dos objetivos de desenvolvimento do milênio. Revibec: Revista Iberoamericana de Economía Ecológica, Barcelona, v. 12, p. 1-15, out. 2009. 
RHEINGANS, R.; DREIBELBIS, R.; FREEMAN. M. C. Beyond the millennium development goals: public health challenges in water and sanitation.

Global Public Health, Chapel Hill, v. 1, n. 1, p. 31-48, 2006.

SALIBA, N. A.; MOIMAZ, S. A. S.; TIANO, A. V. P. Fluoride level in public water supplies of cities from the Northwest region of São Paulo state, Brazil. Journal of Applied Oral Science, São Paulo, v. 14, n. 5, p. 346-350, 2006.

SCHRAMM, F. R.; KOTTOW, M. Principios bioéticos en salud pública: limitaciones y propuestas. Cadernos de Saúde Pública, Rio de Janeiro, v. 17, n. 4, p. 949-956, 2001.

SELBORNE, E. L. A ética do uso da água doce: um levantamento. Brasília, DF: Unesco, 2002.

SILVA, F. S. J. B. et al. Heterocontrole do nível de flúor da água de abastecimento público da cidade de Lins-SP. Revista da Faculdade de Odontologia de Lins, Piracicaba, v. 16, n. 1, p. 22-28, 2004.
TEIXEIRA, J. C.; PUNGIRUM, M. E. M. C. Análise da associação entre saneamento e saúde nos países da América Latina e do Caribe, empregando dados secundários do banco de dados da Organização Pan-Americana de Saúde - OPAS. Revista Brasileira de Epidemiologia, São Paulo, v. 4, n. 4, p. 365-376, 2005.

TOASSI, R. F. C. et al. Heterocontrole da fluoretação da água de abastecimento público de Lages, Santa Catarina, Brasil. Ciência \& Saúde Coletiva, Rio de Janeiro, v. 12, n. 3, p. 717-732, 2007.

TORRES, A. T. G. Hidroterritórios (novos territórios da água): os instrumentos de gestão dos recursos hídricos e seus impactos nos arranjos territoriais. 2007. Dissertação (Mestrado em Geografia) - Universidade Federal da Paraíba, João Pessoa, 2007.

UNESCO - UNITED NATIONS EDUCATIONAL, SCIENTIFIC AND CULTUTAL ORGANIZATION. World water assessment programme: water for people, water for life. Paris, 2003. Disponível em: <http://www.unesco.org/water/wapp/wadr/ ex_summary/ ex_summary_en.pdf $>$. Acesso em: 13 jan. 2010. 